\title{
Analysis of pesticide residues in strawberries and soils by GC-MS/MS, LC-MS/MS and two- dimensional GC-time-of-flight MS comparing organic and integrated pest management farming
}

Virgínia C. Fernandes, Steven J. Lehotay, Lucía Geis-Asteggiante, Hyeyoung Kwon, Hans G.J. Mol, Henk van der Kamp, Nuno Mateus, Valentina F. Domingues and Cristina Delerue-Matos

This study analysed 22 strawberry and soil samples after their collection over the course of 2 years to compare the residue profiles from organic farming with integrated pest management practices in Portugal. For sample preparation, we used the citrate-buffered version of the quick, easy, cheap, effective, rugged, and safe (QuEChERS) method. We applied three different methods for analysis: (1) 27 pesticides were targeted using LC-MS/MS; (2) 143 were targeted using low pressure GC-tandem mass spectrometry (LP-GC-MS/MS); and (3) more than 600 pesticides were screened in a targeted and untargeted approach using comprehensive, two-dimensional gas chromatography time-of-flight mass spectrometry (GC $\times$ GC-TOF-MS). Comparison was made of the analyses using the different methods for the shared samples. The results were similar, thereby providing satisfactory confirmation of both similarly positive and negative findings. No pesticides were found in the organic-farmed samples. In samples from integrated pest management

practices, nine pesticides were determined and confirmed to be present, ranging from $2 \mu \mathrm{kg} \mathrm{kg}^{-1}$ for fluazifop-pbutyl to $50 \mu \mathrm{g} \mathrm{kg}^{-1}$ for fenpropathrin. Concentrations of residues in strawberries were less than European maximum residue limits.

Keywords: pesticide residue confirmatory analysis; chromatography; mass spectrometry; QuEChERS; strawberry; soil; farming practices

\section{Introduction}

Technical innovations in crop protection have been a major reason for globalised food production and distribution over the past several decades. The ease of year-round consumer access to foodstuffs from distant growing regions has depended, in part, on new pesticides that combat the historic foes of food production: weeds, fungi and insect/arachnid pests (Meng et al. 2010). Hundreds of pesticides are widely used in current agri- cultural practices around the world, and it is not uncom- mon for residues of these pesticides to contaminate the environment and remain on food products, especially in fruit and vegetables (EUROPA - Food Safety - Rapid Alert System for Food and Feed - RASFF Portal; Koesukwiwat et al. 2010). In an attempt to avoid exces- sive human and environmental exposure to agrochem-icals, regulators worldwide have established MRLs to protect environmental and consumer health (USDA, MRL database).

Some proponents of organic agriculture believe that organically produced foods are more beneficial to human health than foods produced using conventional farming practices. Some hold an opposing view, and many others doubt if there is any difference (Winter \& Davis 2006). Several studies have reported that there is insufficient evidence to draw valid conclusions, as the scientific research has not proven that organic foods are superior in nutritional quality and safety (RomeroGonzalez et al. 2011; Fernandes et al. 2012). Contrary to what most people believe, 'organic' does not automatically mean 'pesticide-free' or 'chemical-free'. Previously, pesticides were found in food samples grown using organic farming (OF) as well as integrated pest management (IPM) prac- tices (Baker et al. 2002; Lopes \& Simões 2006; Mladenova \& Shtereva 2009; Fernandes et al. 2011, 2012a; Kovacova et al. 2013).

To ensure that proper agricultural practices are being followed, monitoring is required, but the task turns out to be more difficult as the number of targeted and nontargeted pesticides of concern grows. In accordance with today's practices (SANCO/12495/2011 2011), limits of identification (LOI) and quantification (LOQ) in the complex matrices should be $<10 \mathrm{ng} \mathrm{g}^{-1}$. Furthermore, the time and cost of analysis should be kept to a minimum. 

Therefore, simple and rapid methods for screening hundreds of pesticides at trace levels in various matrixes provide the most effective approach to meet regulatory needs.

The widely divergent chemical properties (polarity, volatility, stability, etc.) of pesticides tend to call for the application of different analytical methods (Meng et al. 2010). For non-polar and semi-polar pesticides, the detection of pesticide residues is commonly achieved through analysis with GC coupled to different detectors, particularly MS. For polar and semi-polar compounds, pesticide residue detection is generally achieved using LC-MS/MS (Zhang et al. 2011). LC-MS/MS methods for pesticides are typically devised to target carbamates, phenylureas, anilides, triazoles, macrocyclic lactones, neonicotinoids, strobilurins, triazines, relatively polar organophosphates and other pesticides totalling in the hundreds as frequently reported (Kmellar et al. 2010; Zhang et al. 2011).

For sample preparation prior to MS-based analysis, the QuEChERS approach is commonly used to provide high recoveries of a wide range of pesticides in food and other matrices (Paya et al. 2007; Lehotay et al. 2010; Wilkowska \& Biziuk 2011). The QuEChERS approach has evolved from the original unbuffered version (Anastassiades et al. 2003) to a pair of multi-laboratoryvalidated methods using acetate buffering (AOAC Official Method 2007.01) (Lehotay 2007) or citrate buffering (CEN Standard Method EN 15,662) (Koesukwiwat et al. 2011). QuEChERS is a very flexible template that has been modified for different purposes depending on the analytes, matrices, analytical instruments and analyst pre- ferences (Lehotay et al. 2011).

Ideally, non-targeted analysis capable of detecting any contaminant of concern at concentrations

$>10 \mathrm{ng} \mathrm{g}^{-1}$ in food would be performed. For GCamenable analytes, very wide chemical coverage is achievable with exceptional selectivity, including the power of mass spectral deconvolution and librarysearchable spectra, using comprehensive, 2D GC with time-of-flight mass spectrometry (GC $\times$ GC-TOF-MS) (Amodio et al. 2007; van der Lee et al. 2008). For LCbased analytes, UPLC using high-resolution MS with TOF or orbi-trap techniques provides the current stateof-the-art approach reported in the literature ( $\mathrm{Mol}$ et al. 2012; Wang et al. 2012). Currently, such instrumenta- tion is expensive and not yet fully validated in residue applications, thus targeted monitoring using LC-MS/ MS is more common, which also yields much lower LOI and LOQ in complex samples. Some authors defend that the time of analysis is very important and a fast GC-MS methodology appears in this direction. LP-GC-MS commonly uses a short mega-bore analyti- cal column, connected through a connector to a short, 
narrow restrictor column at the inlet, providing at the injector similar conditions to those of a conventional GC method, while subatmospheric pressure conditions occur throughout the analytical column.

The aim of this study was to use LC-MS/MS and GC- MS/MS for up to 193 targeted pesticides and GC $\times$ GC- TOF-MS for a potentially unlimited number of pesticides in strawberry and soil after rapid sample preparation by QuEChERS. The results would be compared for those pesticides detected, which also provides confirmation and greater confidence in the findings. Samples originated from OF and IPM production, which allowed comparative assessment of pesticide residue levels when using those farming practices.

Materials and methods

Chemicals and materials

Strawberries using OF and IPM practices were collected in the first week of May on 2 consecutive years (2009 and 2010) from a plot near the centre of Portugal. Different varieties of strawberries were collected including Siba, Camarosa, Festival and Albion in both farming approaches. Crop soils from which the strawberries were grown were also collected at the same time. In all, 22 samples were collected (eight batches of strawberries and eight related soils from OF and three batches of strawber- ries and soil from IPM).

The list of pesticides included in the study was selected based on methods from previous studies (Lehotay et al. 2010; Koesukwiwat et al. 2011; Mol et al. 2011) taking into account pesticides used in straw- berry production in Portugal (Lopes \& Simões 2006). For the targeted pesticides in the study, high-purity pesticide standards were obtained from Chemservice (West Chester, PA, USA), the Environmental Protection Agency National Pesticide Repository (Fort Meade, MD, USA), and Dr. Ehrenstorfer GmbH (Augsburg, Germany). The isotopi- cally labelled internal standard (IS), atrazine-d5, was pur- chased from $\mathrm{C} / \mathrm{D} / \mathrm{N}$ Isotopes (Pointe-Claire, QC, Canada). For use as quality control (QC) standards, triphenylphosphate (TPP) was from Sigma-Aldrich (St. Louis, MO, USA) and 4,4'-dichlorobenzophenone was obtained from Sigma-Aldrich (Steinheim, Germany). Acetonitrile (MeCN) was of HPLC grade from J.T. Baker (Phillipsburg, NJ, USA), and formic acid (88\% purity) was obtained from Spectrum (New Brunswick, NJ, USA); deionised water of $18.2 \Omega-\mathrm{cm}$ was prepared with an E-Pure Model D4641 from Barnstead/Thermolyne
(Dubuque, IA, USA).

Commercial QuEChERS extraction packets were obtained from UCT (Bristol, PA, USA) for the citratebuffered version, which contained $6 \mathrm{~g}$ anhydrous MgSO4, 1.5 g sodium chloride, 1.5 g trisodium citrate 
dihydrate and $0.75 \mathrm{~g}$ disodium hydrogenocitrate sesquihy- drate. For dispersive solid-phase extraction ( $d$ SPE) clean- up, the commercial QuEChERS kits included 2 $\mathrm{ml}$ mini- centrifuge tubes containing $150 \mathrm{mg}$ primary secondary amine (PSA) sorbent, $50 \mathrm{mg} \mathrm{C18}$ and $150 \mathrm{mg}$ anhydrous $\mathrm{MgSO}$.

\section{Sample preparation}

For strawberries, $10 \mathrm{~g}$ homogenised strawberries was weighed into a $50 \mathrm{ml}$ centrifuge tube and $10 \mathrm{ml}$ of $\mathrm{MeCN}$ were added. For soil, $5 \mathrm{~g}$ were weighed into a $50 \mathrm{ml}$ centrifuge tube and $10 \mathrm{ml}$ of $\mathrm{MeCN}$ and $3 \mathrm{ml}$ of water were added. All samples were fortified with $100 \mu \mathrm{l}$ of a QC standard (4,4'-dichlorobenzophenone at $\left.10 \mu \mathrm{g} \mathrm{ml}{ }^{-1}\right)$. The

resulting extracts were shaken for $1 \mathrm{~min}$ followed by the addition of a QuEChERS extraction salts packet described above. The centrifuge tubes were capped and shaken vigorously for another $1 \mathrm{~min}$ and centrifuged at $1448 \mathrm{rcf}$ for 5 $\mathrm{min}$ at RT. In the case of soil, the tubes were also sonicated for $5 \mathrm{~min}$ in an ultrasonic bath working at 50/60 $\mathrm{Hz}$ and $100 \mathrm{~W}$ from Selecta (Barcelona, Spain) before centrifugation. An aliquot of $1.5 \mathrm{ml}$ was transferred from the upper layers into a $2 \mathrm{ml}$ mini-centrifuge tube for cleanup, vortexed for $1 \mathrm{~min}$ and centrifuged for $5 \mathrm{~min}$ at $1448 \mathrm{rcf}$ at RT. Subsequently, an aliquot of $900 \mu$ l was transferred into an autosampler vial and $100 \mu \mathrm{l}$ TPP spiking solution $\left(10 \mu \mathrm{g} \mathrm{ml}^{-1}\right)$ were added to all strawberry and soil extracts before analysis.

\section{LP-GC-MS/MS}

Using similar conditions as described previously (Koesukwiwat et al. 2010), the first analyses were per- formed on an Agilent (Palo Alto, CA, USA) 7890A GC- 7000A triple-quadrupole mass spectrometer. Injection of $5 \mu \mathrm{l}$ into the Agilent multimode inlet (MMI) was made using a MPS2 autosampler controlled by Maestro software (Gerstel Corp., Linthicum, MD, USA). The LP-GC separa- tion was conducted on a $15 \mathrm{~m} \times 0.53$ $\mathrm{mm}$ i.d. $\times 1 \mu \mathrm{m}$ film thickness Rti-5ms analytical column coupled to a $5 \mathrm{~m} \times 0.18 \mathrm{~mm}$ i.d. HydroGuard non-coated restriction capillary (both from Restek, Bellefonte, PA, USA). Ultra- high purity helium (Airgas, Radnor, PA, USA) was used as the carrier gas at $2 \mathrm{ml} \mathrm{min}^{-1}$ constant flow rate. The oven temperature was programmed at an initial temperature of $70^{\circ} \mathrm{C}$ (held for $1.5 \mathrm{~min}$ ), then ramped at $80^{\circ} \mathrm{C} \mathrm{min}^{-1}$ to $180^{\circ} \mathrm{C}$, then to $250^{\circ} \mathrm{C}$ at $40^{\circ} \mathrm{C} \mathrm{min}^{-1}$, followed by a $70^{\circ} \mathrm{C}$ $\min ^{-1}$ ramp to $290^{\circ} \mathrm{C}$, where the temperature was held for

4.5 min. The MS transfer line and ion source temperatures were set at $250^{\circ} \mathrm{C}$ and $320^{\circ} \mathrm{C}$, respectively. Electron ionisa- tion energy of $-70 \mathrm{eV}$ was used with a filament-multiplier delay of $3 \mathrm{~min}$. A full autotune of the mass spectrometer using the default parameters of the instrument was

Table 1. Pesticides monitored in the three analytical methods.

Method

Pesticide list

GC Acephate, alachlor, atrazine, atrazine-d5, ${ }^{a}$ azinphos-ethyl, azinphos-methyl, azobenzene, ${ }^{b}$ azoxystrobin, ${ }^{a}$ benzoylurea, ${ }^{\mathrm{b}}$ bifenthrin, bromophos, bromophos-ethyl, bromopropylate, bromoxynil octanoate, bupirimate, buprofezin, butocarboxim, ${ }^{\text {b }}$ butylated hydroxytoluene, ${ }^{\text {b }}$ cadusafos, captafol, ${ }^{a}$ captan, carbaryl, carbofuran, carbophenothion, carfentrazone-ethyl,

chinomethionat, cis-chlordane, trans-chlordane, chlordecone, ${ }^{\mathrm{b}}$ chlorfenvinphos, chlorothalonil, chlorpropham,

chlorpyrifos, chlorpyrifos-methyl, coumaphos, cyanophos, $\alpha$-cyfluthrin, $\beta$-cyfluthrin, $\lambda$-cyhalothrin, $\alpha$ cypermethrin, $\beta$-cypermethrin, cyprodinil, dazomet, de tamethrin, ${ }^{a}$ demeton-s-methyl, demeton-smethyl sulfone, ${ }^{a}$ diazinon, $p p^{\prime}$-dibromobenzophenone, ${ }^{b}$ dichlofenthion, $p p^{\prime}$-dichlorobenzophenone, dicloran, dicrotophos, dicyclopentadiene,

dimepiperate, ${ }^{\mathrm{b}}$ dimethoate, dioxacarb, ${ }^{\mathrm{b}}$ dioxathion, diphenylamine, disulfoton, disulfoton-sulfone, ethalfluralin, ethiolate, ${ }^{b}$ ethion, ethofumesate 2 -keto, ${ }^{b}$ ethoprophos, ethoxyquin, esfenvalerate, ${ }^{a}$ famphur, fenamiphos, fenarimol, fenchlorphos, fenhexamid, fenitrothion, fenobucarb, ${ }^{b}$ fenpropathrin, fensulfothion, fenthion, fenthion-d6, fenthion-sulfone, fenuron, ${ }^{b}$ fenvalerate 1 , fipronil, flamprop-methyl, ${ }^{b}$ fluazifop-butyl, flucythrinate, fludioxonil, flumioxazin, ${ }^{b}$ flurenol-butyl, $b$

t-fluvalinate, folpet, fonofos, furmecyclox, ${ }^{\text {b }}$ heptachlor, heptachlor epoxide (iso A), heptachlor epoxide (iso B),

heptenophos, ioxynil octanoate, ${ }^{b}$ iprodione, isocarbamide, $^{b}$ isofenphos, isoprocarb, ${ }^{b}$ kepone, $^{a}$ kresoximmethyl, leptophos, malathion, mepanipyrim, mepronil, ${ }^{b}$ metalaxyl, methacrifos, methanimidamide $n$-(24dimethylphenyl)- $n^{\prime}$-methyl, ${ }^{b}$ methfuroxam, ${ }^{b}$ methidathion, methiocarb, methyl-parathion, ${ }^{a}$ metolachlor, 
metribuzin, mevinphos (sum isomers), mirex, myclobutanil, cis-nonachlor, trans-nonachlor, 4-nonylphenol, o-phenylphenol, oxadixyl, oxyfluorfen, parathion, ${ }^{a}$ parathion-ethyl, ${ }^{b}$ penconazole, pendimethalin, pentachloroanisole, cis-permethrin, trans-permethrin, phorate, phosalone,

phosmet, phosphamidon, phthalimide, piperonyl butoxide, pirimiphos-ethyl, ${ }^{a}$ pirimiphos-methyl, procymidone, profenofos, propachlor, propargite, propazine,, propetamphos, propham, propiconazole, propoxur, propyzamide,

pyrimethanil, quintozene, quizalofop-ethyl, resmethrin, simazine, spiroxamine, ${ }^{\mathrm{b}}$ sulprofos, tebuconazole, tecnazene, terbucarb, terbufos, terbuthylazine, tetrachlorvinphos, tetraconazole, tetradifon,

tetrahydrophthalimide, tolclofos-methyl,tolylfluanid, triadimefon, triazophos, tridemorph, ${ }^{\text {' }}$ trifluralin, vinclozolin

LC Acephate, acibenzolar-s-methyl, atrazine, atrazine-d5, azoxystrobin, carbaryl, carbofuran, cyazofamid, diazinon, dichlorvos, dimethoate, ethoprop, fenthion-sulfone, imidacloprid, linuron, methomyl, methidathion, omethoate, phosmet, pymetrozine, pyrimethanil, spinosad A, spinosad D, thifensulfuron-methyl, tolclofosmethyl, tolylfluanid, tricyclazole, triflumizole

Notes: ${ }^{\mathrm{a} O n l y}$ monitored by LP-GC-MS/MS.

Only monitored by GC $\times$ GC-TOF/MS. 
performed before each sequence, which typically yielded $1250 \mathrm{~V}$ multiplier voltage. An Agilent MassHunter was used for instrument control and data collection. For the final MRM acquisition method, two ion transitions at the experimentally optimised collision energy (CE) were monitored for each analyte, and dwell time of $2.5 \mathrm{~ms}$ was set for all transitions (inter-dwell delay of $1 \mathrm{~ms}$ ). To detect all analytes, the MRM method was divided into 26 time segments.

\section{$L C-M S / M S$}

LC-MS/MS analysis was performed with an Applied Biosystems (Toronto, ON, Canada) API-3000 triple quadrupole MS/MS with ESI in the positive mode coupled to an Agilent 1100 LC. Applied Biosystems Analyst 1.5 software provided instrument control and data collection. The analy- tical column was a Phenomonex (Torrance, CA, USA) Prodigy ODS-3 $150 \mathrm{~mm} \times 3 \mathrm{~mm}$ i.d., $5 \mu \mathrm{m}$ particle size, coupled to a $4 \mathrm{~mm} \times 3 \mathrm{~mm}$ i.d. Security Guard C18 column.

The column temperature was $30^{\circ} \mathrm{C}$, injection volume was $20 \mu \mathrm{l}$ and flow rate was $0.3 \mathrm{ml} \mathrm{min}-1$. The mobile phase consisted of $0.1 \%$ formic acid in water (A) or MeCN (B). The gradient programme started at $70 \% \mathrm{~A}$ and increased to $100 \%$ B over $8 \mathrm{~min}$ and where it was held for $5.5 \mathrm{~min}$.

\section{GC $\times$ GC-TOF-MS}

For GC $\times$ GC-TOF-MS analysis, a Pegasus-4D system (Leco, St. Joseph, MI, USA) including an Agilent $6890 \mathrm{GC}$ equipped with an Optic-3 PTV injector (Atas, Veldhoven, The Netherlands) was used. The 1D column was $30 \mathrm{~m} \times$ $0.25 \mathrm{~mm}$ i.d. $\times 0.25 \mu \mathrm{m}$ RTX-CL (Restek, Breda, The Netherlands), and the 2D column was $2 \mathrm{~m} \times 0.1 \mathrm{~mm}$ i.d. $\times 0.07 \mu \mathrm{m}$ BPX-50 (SGE, Darmstadt, Germany), mounted in a separate oven installed within the main GC oven. Helium was used as carrier gas at a constant pressure of $47 \mathrm{psi}$. The PTV temperature was programmed

as follows: $20^{\circ} \mathrm{C}(0.5 \mathrm{~min})$ ramp at $0.5^{\circ} \mathrm{C} \mathrm{s}^{-1}$ to $50^{\circ} \mathrm{C}$, ramp at $6^{\circ} \mathrm{C} \mathrm{s} ~^{-1}$ to $280^{\circ} \mathrm{C}$ hold for $20 \mathrm{~min}$. The temperature

programme of the first column (main GC oven) was as

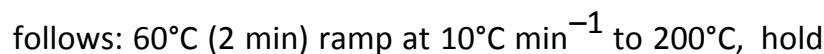
for $0 \mathrm{~min}$, ramp at $7^{\circ} \mathrm{C} \mathrm{min}^{-1}$ to $270^{\circ} \mathrm{C}$, ramp at $10^{\circ} \mathrm{C} \mathrm{min}^{-}$ 1 to $320^{\circ} \mathrm{C}$ hold for $15 \mathrm{~min}$. The temperature of the second oven was programmed from $70^{\circ} \mathrm{C}(2 \mathrm{~min})$ to $360^{\circ} \mathrm{C}$ at a rate of $10^{\circ} \mathrm{C} \mathrm{min}-1$ with a final hold time of 15 $\mathrm{min}$. The modulator temperature offset was $50^{\circ} \mathrm{C}$ relative to the first GC oven temperature. The $2 \mathrm{D}$ separation time (modulation time) was $4.5 \mathrm{~s}$ divided into a hot pulse time

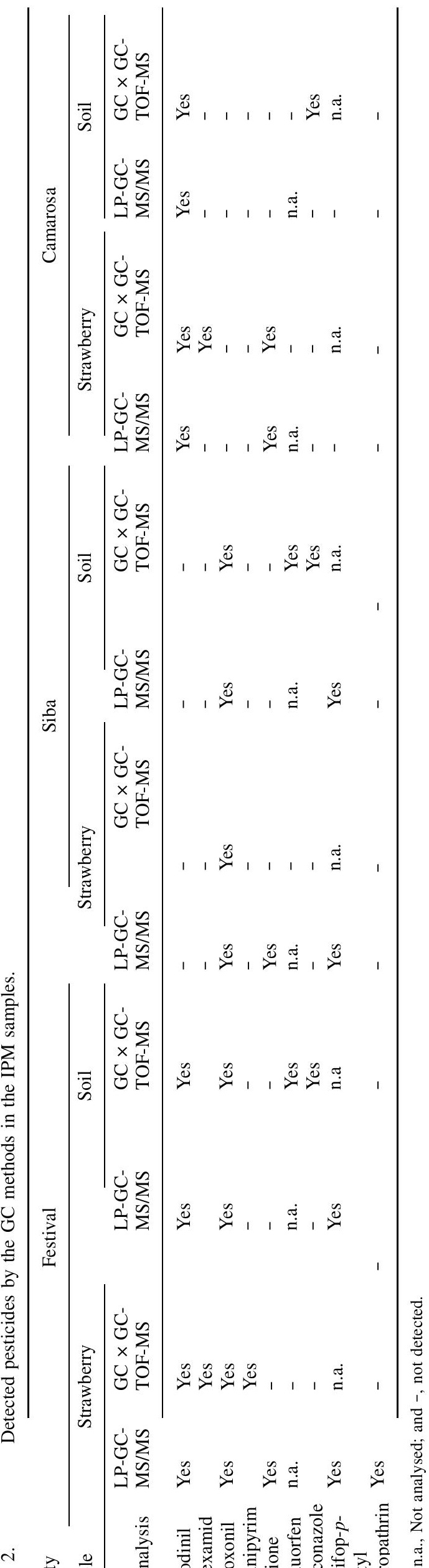


of $0.60 \mathrm{~s}$ and a cold pulse time between the stages of 1.65 s. The transfer line from the secondary oven into the mass spectrometer was maintained at $280^{\circ} \mathrm{C}$, and the ion source was operated at $250^{\circ} \mathrm{C}$. The data acquisition rate was 200 scans $s^{-1}$, covering a mass range of $50-600$ $\mathrm{m} / \mathrm{z}$. The optimisation 

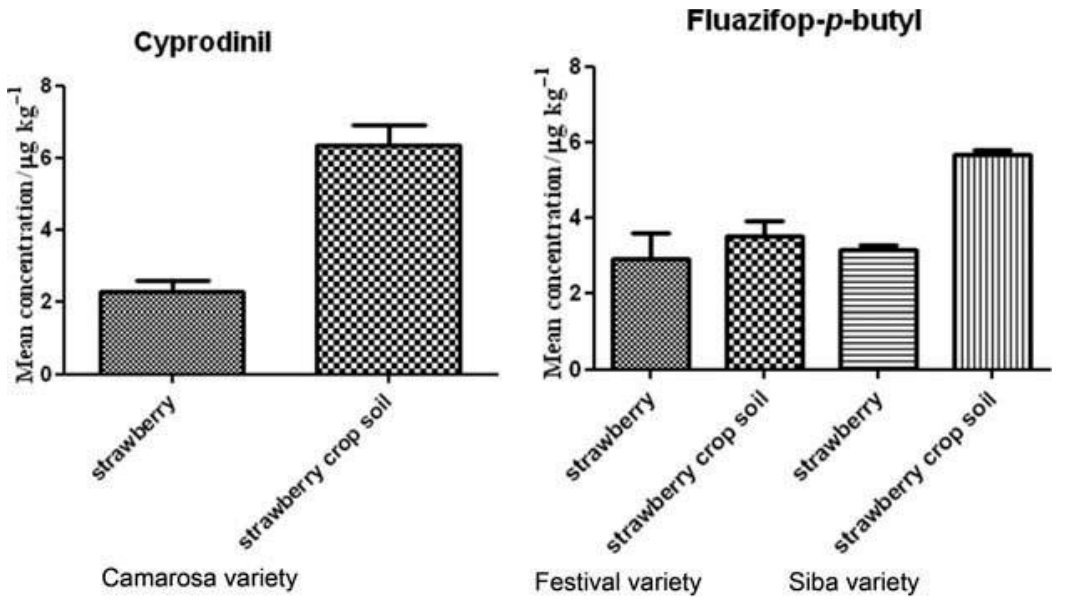

Figure 1. Mean pesticide concentrations found in different IPM samples by LP-GC-MS/MS $(n=3)$.
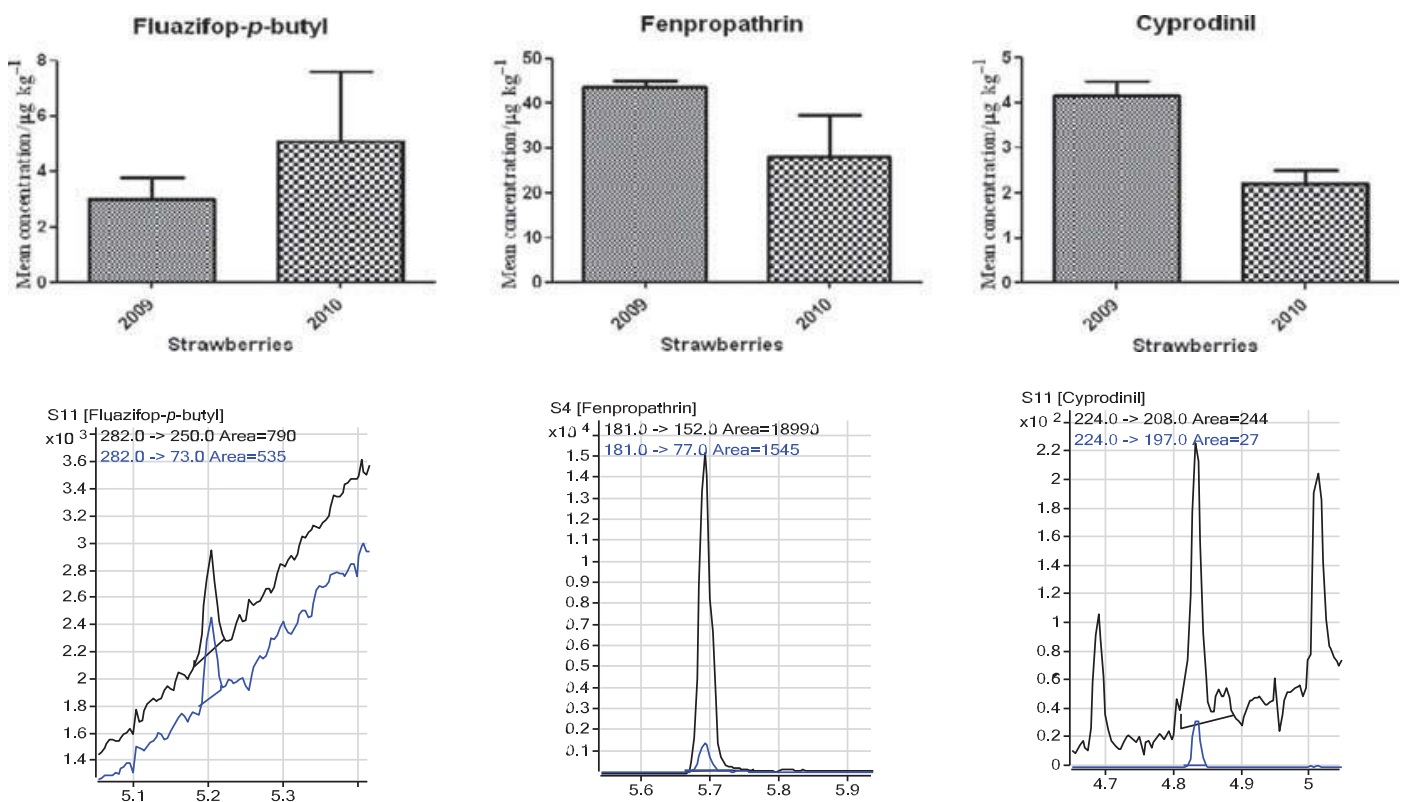

Figure 2. Mean pesticide concentrations found in IPM-grown strawberries using LP-GC-MS/MS analysis $(n=3)$, and examples of their mass spectral identifications.

and validation process for several pesticides was quantitative previously described (Mol et al. 2011). Automated pesticide detection involving deconvolution was performed by ChromaTOF

4.2 software (Leco). The large pesticide database library was created by the injection of reference standards in order to obtain retention time $(t R)$ information and mass spectra. The automated pesticide detection was based on similarity $(>600)$ and $t R$ (within $20 \mathrm{~s}$ of the reference $t \mathrm{R}$ in the database).

Results and discussion

This study describes the combination of three parallel methods:

(1) qualitative identification and 
determination for 143 target pesticides by LPGC-MS/ MS; (2) qualitative screening of 27 targeted pesticides by LC-MS/MS; and (3) qualitative screening of 167 pesti- cides by GC $\times$ GC-TOF-MS. The acquired full-scan MS using TOF-MS detection was used to identify targeted and unexpected compounds. Table 1 shows the list of pesti- cides evaluated by the three chromatographic methods. As shown, some of the pesticides are common in the three methods, which allows for confirmation, and in total 193 different pesticides were included.

The selected pesticides were mainly chosen from pre- existing GC and LC methods to assess the samples mainly for comparison purposes. The chosen pesticides are commonly monitored in many regulatory programmes worldwide. Moreover, these pesticides are representative 

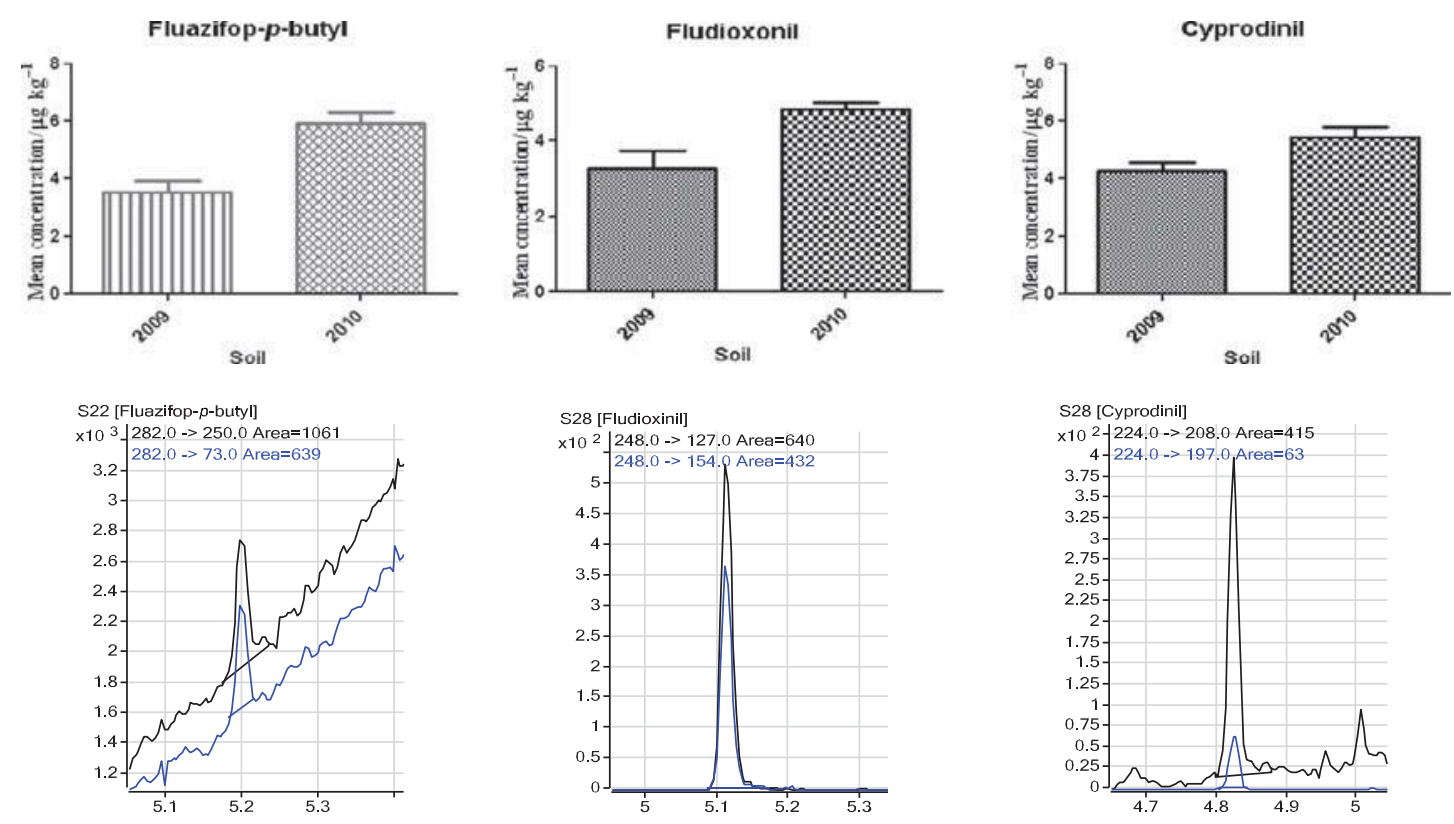

Figure 3. Mean pesticide concentrations found in IPM-grown soils using LP-GC-MS/MS analysis $(n=3)$, and examples of their mass spectralidentification.

different pesticide classes often found at ultra-trace levels in fruits and vegetables. The use of MS/MS in this study was limited to target screening and quantification, but there is an increasing demand for retrospective and non- targeted data analysis possible by the GC $\times$ GC-TOFMS method. Ideally, pesticide monitoring should survey all pesticides in all samples.

The methods have previously been fully validated before their use in this study (Lehotay et al. 2010; Koesukwiwat et al. 2011; Mol et al. 2011). Additional validation of the quantitative MS/MS methods was performed for strawberries and soil. Calibration of matrix- matched standards in the range $5-200 \mu \mathrm{g} \mathrm{kg}^{-1}$ provided $R^{2}$

values higher than 0.99 for all analytes.

\section{Case study of Portuguese strawberries and strawberry crop soils}

None of the 27 targeted pesticides was detected in the LC- MS/MS analyses of the samples. No pesticides were detected in any of the samples in the OF regimen by any of the methods. The two GC-based methods detected those pesticides in the IPM samples as shown in Table 2, which indicates the presence of nine pesticides in 22 analysed samples. The results indicate the presence of at least seven compounds in the strawberries and five in soils. Five pesticides were detected by LP-GC-MS/MS and seven were detected by GC $\times$ GC-TOF-MS. Only three pesticides (cyprodinil, fludioxonil and iprodione) were confirmed to be present in the samples using both methods.
The data showed that some pesticides were detected only by TOF or only by MS/MS, which suggests that the two equipments have different sensitivities and selectivities.

The pesticides (cyprodinil, fludioxonil and fluazifop-pbutyl) found in soil samples were also detected in the corresponding strawberries. The analyses were performed in triplicate for each sample. Figure 1 shows the mean concentrations of cyprodinil and fluazifop- $p$-butyl deter- mined by LP-GC-MS/MS in strawberries of the camarosa, festival and siba varieties, and their soils. The levels detected of cyprodinil were nearly three-fold higher in soils than in the strawberry samples. In the case of fluazi- fop-p-butyl, higher levels were also achieved in soil samples, but only by a factor of 1.2-1.8-fold. Strawberries are grown very low to the soil, so these findings are not surprising.

Mepanipyrim (a fungicide) was shown to be present in IPM-grown strawberries from 2009, and in samples from 2010, iprodione (a fungicide) and fluazifop-p-butyl ( $a$ herbicide) were determined. The fungicides cyprodinil and fludioxonil and the insecticide fenpropathrin were determined in strawberries from both 2009 and 2010. Figures 2 and 3 show the MS/MS results obtained from LP-GC-MS/MS analysis and the mean concentrations of the pesticides.

The herbicide oxyfluorfen and the fungicide tetracona- zole were also found in the strawberry crop soils from 2009. Cyprodinil and fludioxonil were found in the 2010 strawberry crop soils, and fluazifop- $p$ butyl in soils from both years. Figure 4 shows the confirmation offludioxonil 

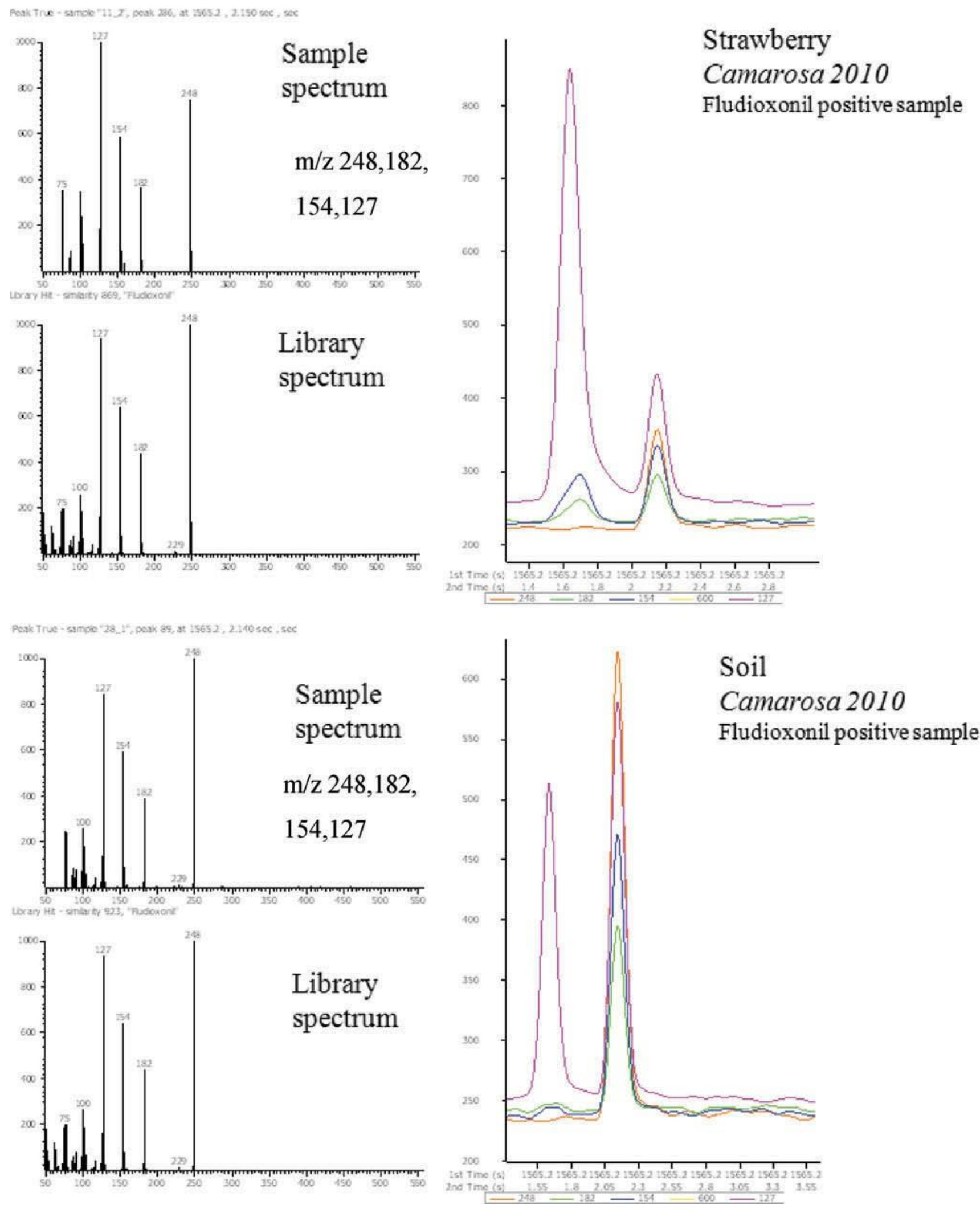

Figure 4. Confirmatory GC $\times$ GC-TOF-MS chromatograms for fludioxonil residue in IPM-grown strawberry and corresponding soil samples. 
by GC $\times$ GC-TOF-MS chromatograms for fludioxonil residues in camarosa IPM crops from 2010.

Overall, the pyrethroid fenpropathrin, which was detected in camarosa, festival and siba strawberries from 2010, gave the highest residue value of $45 \mu \mathrm{g}$ $\mathrm{kg}^{-1}$. All determined concentrations were below the European Union regulatory limits in all strawberry samples, which indicate that the detected pesticides were used legally in the

Portuguese strawberry crops (EU pesticide database; Lopes

\& Simões 2006). For soils, legislation has not been established in to set maximum pesticide levels for Portuguese soils. Most findings of pesticide residues in the different soils by LP-GC-MS/MS analysis were $<6 \mu \mathrm{g} \mathrm{kg}^{-1}$, which is not a cause of concern. Previously studies about IPM and OF systems were performed using ion-trap GC-MS/MS and bifenthrin, mepanipyrim, tetraconazole, malathion, tolylfluanid, lindane, $\beta$-endosulfan, aldrin, cyprodinil, fludioxonil and fluazifop- $p$-butyl were detected (Fernandes et al. 2011, 2012b, 2012c).

In conclusion, the application of this methodology enabled fast and easy, yet effective, monitoring of a long list of pesticides on strawberries and the surrounding soils involved in their production. The combination of the LC$\mathrm{MS} / \mathrm{MS}$, LP-GC-MS/MS and GC $\times$ GC-TOF-MS was very powerful to screen, quantify, identify and confirm the detected residues. Chromatography coupled to triple quadru- pole MS/MS could target 193 pesticides of interest, showing excellent sensitivity and selectivity to provide easy and reli- able data processing and pesticide identifications (fluazifop- $p$-butyl, fludioxinil, fenpropathrin, cyprodinil, iprodione). GC $\times$ GC-TOF-MS was used to identify qualitatively addi- tional pesticides (oxyfluorfen, tetraconazole) and make a confirmation of those already found (iprodione, mepani- pyrim, fludioxonil, fenhexamid, cyprodinil).

Samples from different farming practices in Portugal obtained over the course of 2 years were analysed by this approach. No pesticides were detected in strawberries and soils from OF practices, and nine pesticides were found in samples when using IPM practices, with slightly higher levels occurring in the soils. Based on European Union legislation, all findings were well below maximum per-missible levels.

\section{Funding}

This research was supported by a PhD grant [grant number BD/ 47200/2008] from the Fundação para a Ciência e a Tecnologia, co-financed by POPH/FSE (Programa Operacional Potencial Humano/Fundo Social Europeu); and by grant number PEst-C/ EQB/LA0006/2011.

\section{References}

Amodio ML, Colelli G, Hasey JK, Kader AA. 2007. A compara- tive study of composition and postharvest performance of 
organically and conventionally grown kiwifruits. J Sci Food Agric. 87:1228-1236.

Anastassiades M, Lehotay SJ, Stajnbaher D, Schenck FJ. 2003. Fast and easy multiresidue method employing acetonitrile extraction/partitioning and "dispersive solidphase extrac- tion" for the determination of pesticide residues in produce. J AOAC Int. 86:412-431.

Baker BP, Benbrook CM, lii EG, Benbrook KL. 2002. Pesticide residues in conventional, integrated pest management (IPM)- grown and organic foods: insights from three US data sets. Food Addit Contam. 19:427-446.

EU Pesticide Database [Internet]. [cited 2013 Mar 30]. Available from: http://ec.europa.eu/sanco_pesticides/public/index.cfm?event=substance.selection

EUROPA - Food Safety - Rapid Alert System for Food and Feed

- RASFF Portal [Internet]. [cited 2013 Mar 30]. Available from:

https://webgate.ec.europa.eu/rasffwindow/portal/

Fernandes VC, Domingues VF, Mateus N, Delerue-Matos C. 2011. Organochlorine pesticide residues in strawberries from integrated pest management and organic farming. J Agric Food Chem. 59:7582-7591.

Fernandes VC, Domingues VF, Mateus N, Delerue-Matos C. 2012a. Analysing organochlorine pesticides in strawberry jams using GC-ECD, GC-MS/MS and QuEChERS sample preparation. Food Addit Contam Part A. 29:1074-1084.

Fernandes VC, Domingues VF, Mateus N, Delerue-Matos C. 2012b. Multiresidue pesticides analysis in soils using mod- ified QuEChERS with disposable pipette extraction and dis- persive solid-phase extraction. J Sep Sci. 36:376-382.

Fernandes VC, Domingues VF, Mateus N, Delerue-Matos C. 2012c. Pesticide residues in Portuguese strawberries grown in 20092010 using integrated pest management and organic farming. Environ Sci Pollut Res Int. 19:4184-4192.

Fernandes VC, Subramanian V, Mateus N, Domingues VF, Delerue-Matos C. 2012. The development and optimization of a modified single-drop microextraction method for orga- nochlorine pesticides determination by gas chromatography- tandem mass spectrometry. Microchim Acta. 178:195-202.

Kmellar B, Abranko L, Fodor P, Lehotay SJ. 2010. Routine approach to qualitatively screening 300 pesticides and quantification of those frequently detected in fruit and vegetables using liquid chromatography tandem mass spec- trometry (LC-MS/MS). Food Addit Contam Part A. 27:1415-1430.

Koesukwiwat U, Lehotay SJ, Leepipatpiboon N. 2011. Fast, low- pressure gas chromatography triple quadrupole tandem mass spectrometry for analysis of 150 pesticide residues in fruits and vegetables. J
Chromatogr A. 1218:7039-7050.

Koesukwiwat U, Lehotay SJ, Miao S, Leepipatpiboon N. 2010. High throughput analysis of 150 pesticides in fruits and vegetables using QuEChERS and lowpressure gas chroma- tography-time-of-flight mass spectrometry. J Chromatogr A. 1217:6692-6703.

Kovacova J, Hrbek V, Kloutvorova J, Kocourek V, Drabova L, Hajslova J. 2013. Assessment of pesticide residues in straw- berries grown under various treatment regimes. Food Addit Contam Part A. 30:2123-2135.

Lehotay SJ. 2007. Determination of pesticide residues in foods by acetonitrile extraction and partitioning with magnesium sulfate: collaborative study. J AOAC Int. 90:485-520.

Lehotay SJ, Koesukwiwat U, van der Kamp H, Mol HGJ, Leepipatpiboon N. 2011. Qualitative aspects in the analysis of pesticide residues in fruits and vegetables using fast, low- pressure gas chromatography - timeof-flight mass spectro- metry. J Agric Food Chem. 59:7544-7556. 

Lehotay SJ, Son KA, Kwon H, Koesukwiwat U, Fu WS, Mastovska K, Hoh E, Leepipatpiboon N. 2010. Comparison of QuEChERS sample preparation methods for the analysis of pesticide residues in fruits and vegetables. J Chromatogr A. 1217:25482560.

Lopes A, Simões AM. 2006. Produção integrada em hortícolas -

Família das Rosáceas - Morangueiro. Oeiras: DGPC.

Meng CK, Zweigenbaum J, Furst P, Blanke E. 2010. Finding and confirming nontargeted pesticides using $\mathrm{GC} / \mathrm{MS}$, LC/quadru- pole-time-of-flight MS, and databases. J AOAC Int. 93:703-711.

Mladenova R, Shtereva D. 2009. Pesticide residues in apples grown under a conventional and integrated pest management system. Food Addit Contam Part A. 26:854-858.

Mol HGJ, van der Kamp H, van der Weg $G$, van der Lee $M$, Punt A, de Rijk TC. 2011. Validation of automated library-based qualitative screening of pesticides by comprehensive two- dimensional gas chromatography/time-of-flight mass spec- trometry. J AOAC Int. 94:1722-1740.

Mol HGJ, Zomer P, de Koning M. 2012. Qualitative aspects and validation of a screening method for pesticides in vegetables and fruits based on liquid chromatography coupled to full scan high resolution (Orbitrap) mass spectrometry. Anal Bioanal Chem. 403:2891-2908.

Paya P, Anastassiades M, Mack D, Sigalova I, Tasdelen B, Oliva J, Barba A. 2007. Analysis of pesticide residues using the Quick Easy Cheap Effective Rugged and Safe (QuEChERS) pesticide multiresidue method in combination with gas and liquid chromatography and tandem mass spectrometric detection. Anal Bioanal Chem. 389:1697-1714.

Romero-Gonzalez R, Frenich AG, Vidal JLM, Prestes OD, Grio SL. 2011. Simultaneous determination of pesticides, biopesticides and mycotoxins in organic products applying a quick, easy, cheap, effective, rugged and safe extraction procedure and ultra-high performance liquid chromatogra- phy-tandem mass spectrometry. J Chromatogr A. 1218:1477-1485.

SANCO/12495/2011. 2011. Method validation and quality con-trol procedures for pesticide residues analysis in food and feed. Uppsala: National Food Adminstration.

USDA Maximum Residue Limit Database [Internet]. [cited 2013 Mar 30]. Available from: http://www.fas.usda.gov/htp/ mrl.asp

van der Lee MK, Van der Weg G, Traag WA, Mol HGJ. 2008. Qualitative screening and quantitative determination of pes- ticides and contaminants in animal feed using comprehen- sive two-dimensional gas chromatography with time-of- flight mass spectrometry. J Chromatogr A. 1186:325-339.

Wang J, Chow W, Leung D, Chang J. 2012. Application of ultrahigh-performance liquid chromatography and electro- spray ionization quadrupole orbitrap highresolution mass spectrometry for determination of 166 pesticides in fruits and vegetables. J Agric Food Chem. 60:12088-12104.

Wilkowska A, Biziuk M. 2011. Determination of pesticide resi- dues in food matrices using the QuEChERS methodology. Food Chem. 125:803-812.

Winter CK, Davis SF. 2006. Organic foods. J Food Sci. 71: R117-R124.

Zhang K, Wong JW, Yang P, Tech K, DiBenedetto AL, Lee NS, Hayward DG, Makovi CM, Krynitsky AJ, Banerjee $\mathrm{K}$, et al. 2011. Multiresidue pesticide analysis of agricultural com- modities using acetonitrile salt-out extraction, dispersive solid-phase sample clean-up, and high-performance liquid chromatographytandem mass spectrometry. J Agric Food Chem. 59:7636-7646. 